\title{
Neurobiological mechanisms underlying internet gaming disorder
}

\author{
Aviv Weinstein, BSc, PhD; Michel Lejoyeux, MD, PhD
}

This review summarizes studies on the neurobiological correlates of internet gaming disorder (IGD), presently the most direct approach to analyzing the impact of digital technology and the internet on brain mechanisms. Brain imaging studies have shown that IGD shares, to a large extent, neurobiological alterations that are typical for other addictions, such as: (i) activation in brain regions associated with reward, as evident from cue exposure and craving studies and neurotransmitter systems studies that indicate an involvement of dopamine-mediated reward mechanisms; (ii) reduced activity in impulse control areas and impaired decision making; and (iii) reduced functional connectivity in brain networks that are involved in cognitive control, executive function, motivation, and reward. Moreover, there are structural changes, mainly reduction in gray-matter volume and white-matter density. Comorbidity studies indicate that executive control networks in attention deficit-hyperactivity disorder (ADHD) may increase the susceptibility to develop IGD. Most importantly, this review also outlines findings that show the effects of excessive use of screens, here referring to the playing of computer games, which activate many brain regions associated with cognitive, motor, and sensory function and not directly involved in other forms of addiction. This review describes and summarizes comprehensively the neurobiological correlates of addictive internet use in adolescents and young adults.

Keywords: brain imaging; control inhibition; cue reactivity; decision making; fMRI; internet gaming disorder; reward

\section{Introduction}

Excessive use of certain electronic media, including TV, computer screens, and smartphones, is raising serious concerns among health and educational authorities because of the deleterious effects of such use in children and adolescents. It has recently been shown that, in 5-year-old preschool children, there is an association between increased screen-based media use and reduced microstructural integrity of brain white-matter tracts that are associated with language and literacy skills, tracts that are important in the early years of brain development. ${ }^{1}$ Furthermore, assessment of 4277 adolescents in the Adolescent Brain Cogni- tive Development study (ABCD) via functional magnetic resonance imaging (fMRI) has shown a negative correlation between screen-media activity and cortical thickness. ${ }^{2}$ As cortical thickness naturally declines with age, these findings imply that excessive use of screen media prematurely ages the brain. The study also showed that screen-media use was associated with crystallized and fluid intelligence and that there was a positive association between screen-media use and externalizing but not internalizing psychopathology. The pervasive use of media screens has also been examined in young adults, and heavy media multitaskers are more susceptible to interference from irrelevant environmental stimuli and from irrelevant representations in memory.

Author affiliations: Department of Behavioral Science, Ariel University, Ariel, Israel (Aviv Weinstein); Department of Psychiatry and Addictive Medicine, Maison Blanche Hospital and Bichat-Claude Bernard Hospital, AP-HP, Paris Diderot University, Paris, France (Michel Lejoyeux). Address for correspondence: Aviv Weinstein, Department of Behavioral Science, Ariel University, Ariel, Israel (email: avivwe@ariel.ac.il; avivweinstein@yahoo.com) 


\section{Original article}

Neurobiological mechanisms underlying internet gaming disorder - Weinstein, Lejoyeux

This has been supported by evidence that heavy media multitaskers perform worse on testing of task-switching ability, probably due to impaired ability to ignore irrelevant stimuli." ${ }^{3,4}$ The findings thus far, spanning from early childhood to adolescence, on rapidly growing societal phenomena emphasize the need to assess the effects of media screens on cognitive function and the brain in children, adolescents, and young adults. Specifically, there is extensive research on the excessive use of the internet for gaming and its effects on the brain in young adults and in particular in adolescents. The study of the neurobiological correlates of internet gaming disorder (IGD) appears particularly effective to demonstrate the impact of digital technology and the Internet on brain mechanisms. Furthermore, this evidence has raised major concerns in mental health professionals, and it has led to a major debate as to whether IGD should be classified as a clinical disorder. Brain imaging studies in IGD have been reviewed previously. ${ }^{5-8}$ This review will describe brain imaging studies in IGD, particularly in adolescents from 2014 until December 2019. Keywords were entered into PubMed search using "internet gaming disorder" as a search word. "English language" was used as a search limiter, and publication date was limited from 2014 to December 2019. Studies on treatment and sex differences were excluded due to limitation in the number of studies for this scope. The search yielded 61 studies of IGD and brain imaging.

\section{Brain imaging studies of the resting state in internet gaming disorder}

This section will describe the effects of IGD on the resting state in the brain, elucidated through studies using a functional neuroimaging technique that measures interactions between brain areas when a participant is not executing a specific action. Changes in resting-state brain activity are evaluated through cerebral blood flow (CBF) changes measured by a blood-oxygen-level-dependent (BOLD) signal in fMRI. Early studies reviewed previously ${ }^{6}$ showed that individuals with excessive internet game use had resting-state changes in areas associated with reward and impulse control, memory and learning, the urge to use drugs, inhibition and executive function, sensory-motor coordination, and visual and auditory mechanisms. Enhanced regional homogeneity (ReHo) in the posterior cingulate cortex and lower ReHo in the superior temporal gyrus were shown in IGD participants compared with control participants and participants diagnosed with alcohol-use disorder. ${ }^{9}$ ReHo is a voxel-based measure of brain activity that evaluates the similarity or synchronization between the time series of a given voxel and its nearest neighbors. ReHo can provide information about the local/regional activity of areas throughout the brain. Furthermore, amplitude of low-frequency fluctuation (ALFF) values in the superior frontal gyrus (SFG) were lower in IGD participants, and they correlated negatively with measures of impulsivity. ${ }^{10}$ ALFF is a measure of the amplitude of low-frequency oscillations that reflect the intensity of regional spontaneous brain activity.

In summary, these studies provide evidence for enhanced cognitive function and decreased activity in sensory-motor coordination in the resting state. Some of these changes are associated with addiction, but others may be associated with sensory, cognitive, and motor effects on the brain. Table I summarizes resting-state and structural studies of IGD. ${ }^{9-23}$

\section{Imaging studies on the brain's gray-matter volume and white-matter density}

This section will review studies on the gray matter of the brain, which is composed of neurons that are associated with emotions, perception, memory, and motor control, and the brain's white matter, which consists mostly of glial cells and myelinated axons that transmit signals from the cerebellum to other brain regions. An early study by Kuhn et $\mathrm{al}^{24}$ reported that frequent-video game-playing participants performing the monetary incentive delay task had greater left striatal gray-matter volume and an enhanced activation in the left striatum when exposed to loss. These findings were negatively associated with deliberation time on another task, indicating impaired reward processing. ${ }^{24}$ 


\section{Original article}

Neurobiological mechanisms underlying internet gaming disorder - Weinstein, Lejoyeux

\begin{tabular}{|c|c|c|c|}
\hline CITATION* & METHOD & PARTICIPANTS & MAIN FINDINGS \\
\hline $\begin{array}{l}\text { Sun et al, }{ }^{11} \\
2014\end{array}$ & $\begin{array}{l}\text { Gray-matter diffusion } \\
\text { assessed via diffusional } \\
\text { kurtosis imaging }\end{array}$ & $\begin{array}{l}18 \text { IGD } \\
21 \text { control participants }\end{array}$ & $\begin{array}{l}\text { Lower gray-matter diffusion in the right anterolateral cerebellum, } \\
\text { right inferior and superior temporal gyri, right supplementary motor } \\
\text { area, middle occipital gyrus, right precuneus, postcentral gyrus, right } \\
\text { inferior frontal gyrus, left lateral lingual gyrus, left paracentral lobule, } \\
\text { left ACC, median cingulate cortex, bilateral fusiform gyrus, insula, } \\
\text { PCC, and thalamus. } \\
\text { Higher gray-matter volume in the right inferior and middle temporal } \\
\text { gyri, and right parahippocampal gyrus, and lower } \\
\text { volume in the left precentral gyrus. }\end{array}$ \\
\hline $\begin{array}{l}\text { Wang et al, }{ }^{12} \\
2015\end{array}$ & $\begin{array}{l}\text { Gray-matter volume measured } \\
\text { via MRI }\end{array}$ & $\begin{array}{l}28 \text { IGD } \\
28 \text { control participants }\end{array}$ & $\begin{array}{l}\text { Smaller gray-matter volume of the bilateral ACC, precuneus, } \\
\text { supplementary motor area, superior parietal lobule, left DLPFC, } \\
\text { left insula, and bilateral cerebellum in IGD participants than in } \\
\text { healthy control participants. } \\
\text { Gray-matter volume of the ACC negatively correlated with the } \\
\text { incongruent response errors on the Stroop test. }\end{array}$ \\
\hline $\begin{array}{l}\text { Kim et al, }{ }^{9} \\
2015\end{array}$ & $\begin{array}{l}\text { Regional homogeneity } \\
\text { (ReHo)† measured via MRI }\end{array}$ & $\begin{array}{l}16 \text { IGD } \\
14 \text { alcohol-use disorder } \\
15 \text { control participants }\end{array}$ & $\begin{array}{l}\text { IGD and alcohol-use disorder participants had increased ReHo in the } \\
\text { PCC. IGD participants showed decreased ReHo in the right superior } \\
\text { temporal gyrus compared with alcohol-use disorder and control } \\
\text { partic-ipants. Patients with alcohol-use disorder showed decreased } \\
\text { ReHo in the ACC. }\end{array}$ \\
\hline $\begin{array}{l}\text { Lin et al, }{ }^{13} \\
2015\end{array}$ & $\begin{array}{l}\text { Gray-matter density and } \\
\text { white-matter density changes } \\
\text { assessed by voxel-based } \\
\text { morphometric analysis } \\
\text { in MRI. }\end{array}$ & $\begin{array}{l}35 \text { IGD } \\
36 \text { control participants }\end{array}$ & $\begin{array}{l}\text { Higher fractional anisotropy in the thalamus and left PCC. } \\
\text { Higher fractional anisotropy in the thalamus was associated with } \\
\text { greater severity of internet addiction. }\end{array}$ \\
\hline $\begin{array}{l}\text { Takeuchi et al, }{ }^{14} \\
2016\end{array}$ & $\begin{array}{l}\text { Mean diffusivity assessed via } \\
\text { diffusion tensor imaging }\end{array}$ & $\begin{array}{l}114 \text { boys } \\
126 \text { girls }\end{array}$ & $\begin{array}{l}\text { The amount of videogame play positively correlated with mean } \\
\text { diffusivity in the left middle, inferior, and orbiofrontal cortxs (OFC); } \\
\text { left pallidum; left putamen; left hippocampus; left caudate; right } \\
\text { putamen; right insula; and thalamus in both cross-sectional and } \\
\text { longitudinal analyses. } \\
\text { Higher mean diffusivity in the areas of the left thalamus, left } \\
\text { hippocampus, left putamen, left insula, and left Heschl gyrus was } \\
\text { associated with lower intelligence. }\end{array}$ \\
\hline $\begin{array}{l}\text { Yuan et al, } \\
2016\end{array}$ & $\begin{array}{l}\text { Assessment of white-matter } \\
\text { integrity and connectivity }\end{array}$ & $\begin{array}{l}28 \text { IGD adolescents } \\
25 \text { control participants }\end{array}$ & $\begin{array}{l}\text { Reduced fractional anisotropy in the ACC/right DLPFC pathways } \\
\text { in IGD. }\end{array}$ \\
\hline $\begin{array}{l}\text { Zhai et al, }{ }^{16} \\
2017\end{array}$ & $\begin{array}{l}\text { White-matter integrity } \\
\text { measured via diffusion tensor } \\
\text { imaging }\end{array}$ & $\begin{array}{l}16 \text { right-handed adolescents } \\
\text { with IGD } \\
16 \text { control participants }\end{array}$ & $\begin{array}{l}\text { Reduced nodal efficiency in frontal cortex, ACC, and pallidium in } \\
\text { IGD. Global efficiency of the white-matter network correlated with } \\
\text { the IAT scores in IGD. }\end{array}$ \\
\hline $\begin{array}{l}\text { Jeong et al, }{ }^{17} \\
2016\end{array}$ & $\begin{array}{l}\text { Assessment of white-matter } \\
\text { integrity and connectivity }\end{array}$ & $\begin{array}{l}181 \text { male patients including: } \\
58 \text { IGD subjects without } \\
\text { psychiatric comorbidity } \\
26 \text { male control participants }\end{array}$ & $\begin{array}{l}\text { Increased fractional anisotropy values within forceps minor, right } \\
\text { anterior thalamic radiation; right corticospinal tract; right inferior } \\
\text { longitudinal fasciculus; right cingulum to hippocampus; and right } \\
\text { inferior fronto-occipital fasciculus (IFOF) decreases in radial diffusivity } \\
\text { value within forceps minor, right anterior thalamic radiation and } \\
\text { IFOF relative to control subjects }\end{array}$ \\
\hline
\end{tabular}

Table I (continued overleaf). Resting-state and structural studies of internet gaming disorder.

* Studies arranged chronologically by publication year. tRegional Homogeneity (ReHo) is a voxel-based measure of brain activity that evaluates the similarity or synchronization between the time series of a given voxel and its nearest neighbors. This measure is based on the hypothesis that intrinsic brain activity is manifested by clusters of voxels rather than single voxels. ReHo can provide information about the local/regional activity of regions throughout the brain. ACC, anterior cingulate cortex (ACC); DLPFC, dorsolateral prefrontal cortex; IAT, internet addiction test; MRI, magnetic resonance imaging; OFC, orbitofrontal cortex; PCC, posterior cingulate cortex; RGU, recreational internet game use. 


\section{Original article}

Neurobiological mechanisms underlying internet gaming disorder - Weinstein, Lejoyeux

\begin{tabular}{|c|c|c|c|}
\hline CITATION* & METHOD & PARTICIPANTS & MAIN FINDINGS \\
\hline $\begin{array}{l}\text { Sun et al, }{ }^{10} \\
2019\end{array}$ & $\begin{array}{l}\text { Resting-state cerebral activity } \\
\text { alterations assessed via } \\
\text { amplitude of low-frequency } \\
\text { fluctuation (ALFF) and } \\
\text { functional connectivity }\end{array}$ & $\begin{array}{l}30 \text { male IGD) } \\
23 \text { female IGD } \\
30 \text { male and } 22 \text { female } \\
\text { age-matched healthy } \\
\text { control participants }\end{array}$ & $\begin{array}{l}\text { Greater ReHo* in the brain stem, inferior parietal lobule, cerebellum, } \\
\text { and middle frontal gyrus. Lower ReHo in occipital and parietal areas. }\end{array}$ \\
\hline $\begin{array}{l}\text { Seok et al, }{ }^{18} \\
2018\end{array}$ & $\begin{array}{l}\text { Assessment of resting-state } \\
\text { gray-matter } \\
\text { volume and functional } \\
\text { connectivity }\end{array}$ & $\begin{array}{l}20 \text { IGD } \\
20 \text { age- and sex-matched } \\
\text { healthy control participants }\end{array}$ & $\begin{array}{l}\text { IGD severity was positively correlated with gray-matter volume in } \\
\text { the left caudate and it was negatively associated with functional } \\
\text { connectivity between the left caudate and the right middle frontal } \\
\text { gyrus. }\end{array}$ \\
\hline $\begin{array}{l}\text { Pan et al, }{ }^{19} \\
2018\end{array}$ & $\begin{array}{l}\text { Assessment of resting-state } \\
\text { gray-matter volume }\end{array}$ & 67 male adolescents & $\begin{array}{l}\text { IAT score was negatively correlated with gray-matter volumes of } \\
\text { the bilateral postcentral gyri, the bilateral precentral gyri, the right } \\
\text { precuneus, the left posterior midcingulate cortex, the left inferior } \\
\text { parietal lobe, and the right middle frontal gyrus. }\end{array}$ \\
\hline $\begin{array}{l}\text { Lee et al, }{ }^{20} \\
2018\end{array}$ & $\begin{array}{l}\text { Assessment of resting-state } \\
\text { gray-matter volume }\end{array}$ & $\begin{array}{l}45 \text { male adults with IGD } 35 \\
\text { age-matched male control } \\
\text { participants }\end{array}$ & $\begin{array}{l}\text { IGD subjects had thinner cortices in the right rostral ACC, right } \\
\text { lateral OFC, and left pars orbitalis than controls. } \\
\text { Smaller gray-matter volume in the right caudal ACC and left pars } \\
\text { orbital-is in IGD subjects. } \\
\text { Thinner cortex of the right lateral OFC in IGD subjects correlated with } \\
\text { higher cognitive impulsivity. } \\
\text { Whole-brain analysis in IGD subjects revealed thinner cortices in } \\
\text { the right supplementary motor area, left frontal eye field, superior } \\
\text { parietal lobule, and posterior cingulate cortex. }\end{array}$ \\
\hline $\begin{array}{l}\text { Dong et al, }{ }^{21} \\
2018\end{array}$ & $\begin{array}{l}\text { Assessment of white-matter } \\
\text { integrity }\end{array}$ & $\begin{array}{l}42 \text { IGD } \\
44 \text { RGU participants }\end{array}$ & $\begin{array}{l}\text { Increased fractional anisotropy in the bilateral anterior thalamic } \\
\text { radiation, anterior limb of the internal capsule, bilateral corticospinal } \\
\text { tract, bilateral inferior fronto-occipital fasciculus, corpus callosum, } \\
\text { and bilteral inferior longitudinal fasciculus. } \\
\text { Internet-addiction severity was positively correlated with fractional } \\
\text { anisotropy values. }\end{array}$ \\
\hline $\begin{array}{l}\text { Wang et al, } \\
2018\end{array}$ & $\begin{array}{l}\text { Assessment of cortical } \\
\text { thickness and volume }\end{array}$ & $\begin{array}{l}38 \text { IGD } \\
66 \text { RGU participants }\end{array}$ & $\begin{array}{l}\text { IGD showed decreased cortical thickness in the left lateral OFC, } \\
\text { inferior parietal lobule, bilateral cuneus, precentral gyrus, and right } \\
\text { middle temporal gyrus. } \\
\text { Reduced cortical volume in the left superior temporal gyrus and right } \\
\text { supra marginal gyrus in IGD. } \\
\text { Whole-brain correlational analysis indicated different correlations } \\
\text { between the two groups. }\end{array}$ \\
\hline $\begin{array}{l}\text { Wang et al, }{ }^{22} \\
2018\end{array}$ & $\begin{array}{l}\text { Assessment of cortical } \\
\text { thickness and volume }\end{array}$ & $\begin{array}{l}48 \text { IGD male youths } \\
32 \text { age- and education- } \\
\text { matched control } \\
\text { participants }\end{array}$ & $\begin{array}{l}\text { IGD showed increased cortical thickness in the bilateral insulae and } \\
\text { the right inferior temporal gyrus. } \\
\text { Decreased cortical thickness in bilateral superior temporal sulci, the } \\
\text { right inferior parietal cortex, the right precuneus, the right precentral } \\
\text { gyrus, and the left middle temporal gyrus. } \\
\text { A positive correlation between the left insular cortical thickness and } \\
\text { symptom severity. }\end{array}$ \\
\hline
\end{tabular}

Table I (continued). Resting-state and structural studies of internet gaming disorder.

* Studies arranged chronologically by publication year. TRegional Homogeneity (ReHo) is a voxel-based measure of brain activity that evaluates the similarity or synchronization between the time series of a given voxel and its nearest neighbors. This measure is based on the hypothesis that intrinsic brain activity is manifested by clusters of voxels rather than single voxels. ReHo can provide information about the local/regional activity of regions throughout the brain. ACC, anterior cingulate cortex (ACC); DLPFC, dorsolateral prefrontal cortex; IAT, internet addiction test; MRI, magnetic resonance imaging; OFC, orbitofrontal cortex; PCC, posterior cingulate cortex; RGU, recreational internet game use. Parts of Tables I and II reproduced with permission from ref 6: Weinstein A, Livny A, Weizman A. New developments in brain research of internet and gaming disorder. Neurosci Biobehav Rev. 2017;75:314-330. Copyright @ Elsevier 2017 


\section{Original article}

Neurobiological mechanisms underlying internet gaming disorder - Weinstein, Lejoyeux

IGD severity was associated with gray-matter volume in the left caudate and was negatively associated with functional connectivity between the left caudate and the right middle frontal gyrus, which mediate reward and cognitive control. ${ }^{18}$

In adolescents, IGD was associated with changes in graymatter volumes in brain regions involved in sensory-motor processes and cognitive control ${ }^{19}$ evaluating reward, error processing, and adjusting behavior, ${ }^{20}$ impulse control, attention, emotional regulation, and motor function. ${ }^{11}$ Reduced gray-matter volume was reported in the prefrontal cortex and the amygdala, and the volume of these regions was associated with measures on the Barratt Impulsiveness Scale. ${ }^{13}$ An inverse relationship was found between low gray-matter volume of the anterior cingulate cortex (ACC) and incongruent response errors on the Stroop task. ${ }^{12}$

Early structural studies reviewed previously ${ }^{6}$ have shown evidence for reduced gray-matter density in brain regions associated with motor, attention, and cognitive control and reduced white-matter volume in brain regions associated with memory, and sensory and motor neurotransmission in IGD. Lower gray-matter volume was found in several brain regions. Reduced fractional anisotropy was shown in other white-matter regions. Further reports have indicated reduced gray-matter volume in brain regions associated with motor and cognitive control and reduced white-matter volume in brain regions associated with cognitive control and planning. Higher white-matter density in the thalamus and left posterior cingulate cortex was associated with greater severity of IGD. ${ }^{12}$
There is also evidence for reduced white-matter volume in brain regions that are associated with inhibition, decision making, and emotional regulation, and reduced fractional anisotropy in the ACC and the dorsolateral prefrontal cortex (DLPFC) was shown in IGD and associated with performance on the Stroop task. ${ }^{15}$ Video game playing correlated with delayed development of several brain regions such as hippocampus, orbitofrontal cortex (OFC), pallidum, caudate/putamen insula, and the thalamus. ${ }^{14}$ Low intelligence was associated with high diffusion measures in brain regions including the hippocampus, thalamus, putamen, and the insula. ${ }^{14}$ Reduced white-matter in the frontal cortex, ACC, and the pallidum was reported in IGD. ${ }^{16}$ There is further evidence for increased white-matter density and decreased diffusion in fiber tracts in the frontal cortex. ${ }^{17}$ Finally, they showed increased fractional anisotropy in tracts linking reward circuitry and sensory and motor control systems, and these were associated with internet addiction severity. ${ }^{21}$

To sum up, the studies reviewed have shown evidence for long-term changes in gray-matter volume and white-matter density in brain regions associated with memory, attention, impulse control, emotional regulation, and motor function in IGD. Some of the reported effects of IGD are associated with characteristics of addiction, such as reward and impulsivity, whereas others may result from changes to attention, emotional regulation, and motor functions in the brain.

Figure 1 shows brain regions with reduced gray-matter volume in frequent IGD players.

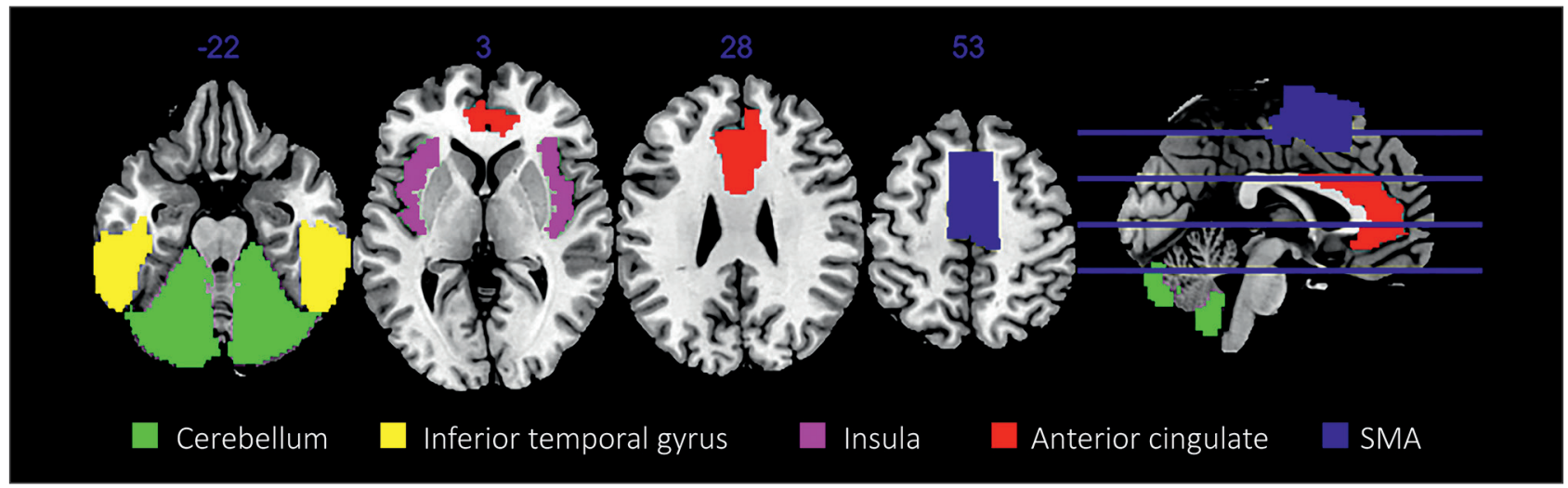

Figure 1. Regions that showed reduced gray-matter volume in internet gaming disorder (IGD) participants in more than two studies. SMA, supplementary motor area. Figure reproduced from ref 6: Weinstein A, Livny A, Weizman A. New developments in brain research of internet and gaming disorder. Neurosci Biobehav Rev. 2017;75:314-330. Copyright ( Elsevier 2017 


\section{Original article}

Neurobiological mechanisms underlying internet gaming disorder - Weinstein, Lejoyeux

\section{Cortical thickness}

Early studies (see ref 6 for review) showed contradictory evidence pertaining to cortical thickness in IGD: some reported enhanced cortical thickness in frontal and temporal areas in adolescents with IGD who performed the Stroop task; some reported decreased cortical thickness. Cortical thickness of the OFC correlated with low performance on the Stroop task. Reduced cortical thickness in the lateral OFC was shown in male adolescents with IGD. Decreased cortical thickness in brain regions that are involved in cognitive control, decision making, and reward/loss processing (OFC, inferior parietal lobe, cuneus, precentral gyrus, and right middle temporal gyrus) was reported in IGD compared with recreational internet game use. ${ }^{22}$ Finally, adolescents with IGD showed decreased cortical thickness in distributed cerebral areas and had a positive correlation between the left insular cortical thickness and symptom severity. ${ }^{23}$

In summary, the studies reviewed so far showed changes in cortical thickness in regions associated with addiction processes such as reward, but also with regions associated with executive function and decision making. The conflicting results of enhanced and reduced cortical thickness indicate that the findings are not robust and that changes in cortical thickness merit further study.

\section{Neuroimaging studies of functional connectivity in internet gaming disorder}

The aim of this section is to review studies on functional connectivity, which measures the level of coactivation of resting-state fMRI time-series between brain regions. Early studies in IGD (see review in ref 6) showed increased functional connectivity between brain regions that are associated with signal processing, cognitive regulation, and auditory-verbal memory, and decreased functional connectivity with brain regions that are associated with evaluation and expectancy of reward in smokers with IGD. Reduced functional connectivity was shown in brain regions associated with executive function and increased functional connectivity in brain regions associated with sensory-motor processing. ${ }^{25}$ Reduced functional connectivity correlated with executive control. ${ }^{26}$ Increased volume of the caudate and nucleus accumbens (NA) and reduced functional connectivity in brain areas that are associated with reward were reported in young adults with IGD. ${ }^{27}$
Early studies in adolescents with IGD (see review in ref 6) showed reduced functional connectivity in cortical-subcortical circuits related to drug addiction. Recent studies have also shown an impaired functional connectivity in brain regions associated with memory and learning, executive function, sensory and motor processing, ${ }^{27}$ and in areas associated with reward (prefrontal cortex and striatal circuits). ${ }^{28}$

Individuals with IGD had greater functional connectivity between the precuneus and brain regions associated with attention, salience, self-monitoring, and craving. ${ }^{29}$ However, the nucleus accumbens and the medial OFC in subjects with this disorder were shown to have lower resting-state functional connectivity with the ventral tegmental area. ${ }^{30}$ Treatment for this disorder with equine-assisted activities and therapies (EAAT) has improved anxiety and avoidance attachment scores and has increased functional connectivity in affective networks, including the amygdala and the frontal orbital gyrus. ${ }^{31}$ Subjects with this disorder were shown to have functional connectivity of the DLPFC with large-scale brain networks, ${ }^{32}$ and adolescents with IGD had increased functional connectivity in brain regions involved in working memory, spatial orientation, and attention processing. ${ }^{33}$

Lower functional connectivity in IGD has been shown to affect executive control function and to have an inverse relationship with the Stroop effect. ${ }^{34}$ Impulsivity has also been inversely associated with functional connectivity in brain regions such as the amygdala, DLPFC, and the $\mathrm{OFC}^{34}$ and has been associated with changes in the frontal-limbic networks. ${ }^{35}$ Participants with IGD also showed increased volumes of the ventral striatum (nucleus accumbens) and dorsal striatum (caudate). ${ }^{36}$

To sum up, the studies so far have shown decreased functional connectivity in IGD in brain networks that are involved in cognitive control, executive function, motivation, and reward. Some of the changes in functional connectivity associated with motivation, craving, and reward are associated with addiction, whereas others may result from changes in executive function and sensory-motor processing that are not related to addiction per se.

Table II summarizes studies on functional connectivity in IGD. ${ }^{15,25-27,29-40}$ 


\section{Original article}

Neurobiological mechanisms underlying internet gaming disorder - Weinstein, Lejoyeux

\begin{tabular}{|c|c|c|c|}
\hline CITATION* & METHOD & PARTICIPANTS & MAIN FINDINGS \\
\hline $\begin{array}{l}\text { Wee et al, }{ }^{27} \\
2014\end{array}$ & $\begin{array}{l}\text { Functional connectivity in } \\
\text { fMRI }\end{array}$ & $\begin{array}{l}17 \text { IGD adolescents } \\
16 \text { control participants }\end{array}$ & $\begin{array}{l}\text { Disruption of functional connectivity in the frontal, occipital, and } \\
\text { parietal lobes. } \\
\text { Functional connectivity with the frontal, occipital, and parietal } \\
\text { lobes correlated with IGD severity. }\end{array}$ \\
\hline $\begin{array}{l}\text { Chen et al, }{ }^{37} \\
2014\end{array}$ & $\begin{array}{l}\text { Functional connectivity in } \\
\text { fMRI }\end{array}$ & $\begin{array}{l}29 \text { IGD smokers } \\
22 \text { IGD nonsmokers } \\
30 \text { control participants }\end{array}$ & $\begin{array}{l}\text { Decreased resting-state functional connectivity with posterior } \\
\text { cingulate cortex in the right gyrus rectus. } \\
\text { Increased resting-state functional connectivity in the left middle } \\
\text { frontal gyrus in smokers with IGD compared with nonsmokers } \\
\text { with IGD. }\end{array}$ \\
\hline $\begin{array}{l}\text { Dong et al, }{ }^{26} \\
2015\end{array}$ & $\begin{array}{l}\text { Functional connectivity in } \\
\text { fMRI }\end{array}$ & $\begin{array}{l}35 \text { IGD } \\
36 \text { control participants }\end{array}$ & $\begin{array}{l}\text { Lower functional connectivity in executive-control network. } \\
\text { Functional-connectivity measures in executive-control networks } \\
\text { were negatively correlated with Stroop effect and positively } \\
\text { correlated with brain activations in executive-control regions across } \\
\text { groups. }\end{array}$ \\
\hline $\begin{array}{l}\text { Ko et al, } \\
2015\end{array}$ & $\begin{array}{l}\text { Gray-matter density and } \\
\text { functional connectivity in } \mathrm{fMRI}\end{array}$ & $\begin{array}{l}30 \text { male IGD } \\
30 \text { control participants }\end{array}$ & $\begin{array}{l}\text { Lower gray-matter density in the bilateral amygdala and higher } \\
\text { impulsivity. } \\
\text { Lower functional connectivity with the left amygdala over the left } \\
\text { DLPFC and with the right amygdala over the left DLPFC and OFC. } \\
\text { Higher functional connectivity with the bilateral amygdala over } \\
\text { the contralateral insula. } \\
\text { Functional connectivity between the left amygdala and DLPFC } \\
\text { negatively correlated with impulsivity. } \\
\text { Functional connectivity of the right amygdala to the left DLPFC } \\
\text { and OFC also negatively correlated with impulsivity. }\end{array}$ \\
\hline $\begin{array}{l}\text { Hong et al, } \\
2015\end{array}$ & $\begin{array}{l}\text { Functional connectivity } \\
\text { in fMRI in subdivisions of } \\
\text { striatum }\end{array}$ & $\begin{array}{l}12 \text { male IGD adolescents } \\
11 \text { male control participants }\end{array}$ & $\begin{array}{l}\text { Reduced dorsal putamen functional connectivity with the posterior } \\
\text { insula-parietal operculum. } \\
\text { Time spent playing online games predicted significantly greater } \\
\text { functional connectivity between the dorsal putamen and bilateral } \\
\text { primary somatosensory cortices. } \\
\text { Lower functional connectivity between the dorsal putamen and } \\
\text { bilateral sensorimotor cortices in healthy control participants. }\end{array}$ \\
\hline $\begin{array}{l}\text { Wang et al, } \\
2015\end{array}$ & $\begin{array}{l}\text { Functional connectivity and } \\
\text { voxel-mirrored homotopic } \\
\text { connectivity (VMHC) method }\end{array}$ & $\begin{array}{l}17 \text { IGD } \\
24 \text { healthy control } \\
\text { participants }\end{array}$ & $\begin{array}{l}\text { Decreased VMHC between the left and right superior frontal gyrus } \\
\text { (orbital part), inferior frontal gyrus (orbital part), middle frontal } \\
\text { gyrus, and superior frontal gyrus. }\end{array}$ \\
\hline $\begin{array}{l}\text { Zhang et } \text { al, }^{30} \\
2016\end{array}$ & $\begin{array}{l}\text { Functional connectivity of } \\
\text { the insula in fMRI }\end{array}$ & $\begin{array}{l}74 \text { IGD young adults } \\
41 \text { control participants }\end{array}$ & $\begin{array}{l}\text { Enhanced functional connectivity between the anterior insula and } \\
\text { a network of regions including ACC, putamen, angular gyrus, and } \\
\text { precuneous. } \\
\text { Stronger functional connectivity between the posterior insula and } \\
\text { post-central gyrus, precentral gyrus, supplementary motor area, } \\
\text { superior temporal gyrus. } \\
\text { IGD severity was positively associated with connectivity between } \\
\text { the anterior insula and angular gyrus, and superior temporal gyrus, } \\
\text { and with connectivity between the posterior insula and superior } \\
\text { temporal gyrus. } \\
\text { Duration of internet gaming was positively associated with } \\
\text { connectivity between the anterior insula and ACC. }\end{array}$ \\
\hline $\begin{array}{l}\text { Cai et al, }{ }^{40} \\
2016\end{array}$ & $\begin{array}{l}\text { Functional connectivity } \\
\text { in fMRI in striatal nuclei } \\
\text { (caudate, putamen, } \\
\text { and nucleus accumbens) } \\
\text { volumes }\end{array}$ & $\begin{array}{l}27 \text { IGD adolescents } \\
30 \text { control participants }\end{array}$ & $\begin{array}{l}\text { Increased volumes of dorsal striatum (caudate) and ventral striatum } \\
\text { (nucleus accumbens) and more errors on the Stroop task. } \\
\text { Caudate volume correlated with Stroop task performance, and } \\
\text { nucleus accumbens volume was associated with the internet } \\
\text { addiction test score in the IGD group. }\end{array}$ \\
\hline
\end{tabular}

Table II (continued overleaf). Studies of functional connectivity in fMRI.

*Studies arranged chronologically by year. ACC, anterior cingulate cortex; DLPFC, dorsolateral prefrontal cortex; fMRI, functional magnetic resonance imaging; IGD, internet gaming disorder; OFC, orbitofrontal cortex;

VMHC, voxel-mirrored homotopic connectivity; VTA/SN, ventral tegmental area/substantia nigra 


\section{Original article}

Neurobiological mechanisms underlying internet gaming disorder - Weinstein, Lejoyeux

\begin{tabular}{|c|c|c|c|}
\hline CITATION* & METHOD & PARTICIPANTS & MAIN FINDINGS \\
\hline $\begin{array}{l}\text { Du et al, }{ }^{34} \\
2017\end{array}$ & $\begin{array}{l}\text { Resting-state functional } \\
\text { connectivity density in fMRI }\end{array}$ & $\begin{array}{l}27 \text { male IGD adolescents } \\
35 \text { healthy control participants }\end{array}$ & $\begin{array}{l}\text { IGD adolescents exhibited higher global/long-range resting-state } \\
\text { functional connectivity in the bilateral dorsal lateral prefrontal } \\
\text { cortex (DLPFC) and the right inferior temporal cortex/fusiform than } \\
\text { healthy control participants. }\end{array}$ \\
\hline $\begin{array}{l}\text { Jin et al, }{ }^{29} \\
2016\end{array}$ & Functional connectivity & $\begin{array}{l}25 \text { IGD adolescents } \\
21 \text { age- and gender-matched } \\
\text { control participants }\end{array}$ & $\begin{array}{l}\text { Decreased functional connectivity between the insula, and } \\
\text { temporal and occipital cortices and dorsal striatum, pallidum, and } \\
\text { thalamus in IGD. } \\
\text { Some of those changes were associated with the severity of IGD. }\end{array}$ \\
\hline $\begin{array}{l}\text { Wang et al, }{ }^{25} \\
2016\end{array}$ & Functional connectivity & $\begin{array}{l}37 \text { IGD } \\
35 \text { matched control } \\
\text { participants }\end{array}$ & $\begin{array}{l}\text { Reduced connectivity in the prefrontal cortex, left posterior } \\
\text { cingulate cortex, right amygdala, and bilateral lingual gyrus, and } \\
\text { increased functional connectivity in sensory-motor-related brain } \\
\text { networks in IGD. }\end{array}$ \\
\hline $\begin{array}{l}\text { Park et al, } \\
2017\end{array}$ & $\begin{array}{l}\text { Functional connectivity } \\
\text { in fMRI }\end{array}$ & $\begin{array}{l}19 \text { IGD adolescents } \\
20 \text { age-matched control } \\
\text { participants }\end{array}$ & $\begin{array}{l}\text { Higher impulsiveness, higher global efficiency, and lower local } \\
\text { efficiency pathological states. } \\
\text { Topological alterations were specifically attributable to inter- } \\
\text { regional connections incident on the frontal region, and the degree } \\
\text { of impulsiveness was associated with the topological alterations } \\
\text { over the frontal-limbic connections. }\end{array}$ \\
\hline $\begin{array}{l}\text { Yuan et al, }{ }^{15} \\
2016\end{array}$ & $\begin{array}{l}\text { Functional connectivity } \\
\text { in fMRI }\end{array}$ & $\begin{array}{l}28 \text { IGD adolescents } \\
25 \text { control participants }\end{array}$ & $\begin{array}{l}\text { Reduced fractional anisotropy in salience network, right central } \\
\text { executive network tracts, and between-network (the ACC-right } \\
\text { DLPFC tracts). } \\
\text { Correlation between the effective and structural connection from } \\
\text { salience network to central executive network and the number of } \\
\text { errors during incongruent condition in Stroop task in both IGD } \\
\text { and control participants. }\end{array}$ \\
\hline $\begin{array}{l}\text { Kang et al, }{ }^{32} \\
2018\end{array}$ & $\begin{array}{l}\text { Resting-state functional } \\
\text { connectivity }\end{array}$ & $\begin{array}{l}15 \text { IGD adolescents with } \\
\text { insecure attachment } \\
15 \text { healthy control } \\
\text { adolescents with secure } \\
\text { attachment }\end{array}$ & $\begin{array}{l}\text { Functional connectivity from the left amygdala to the left } \\
\text { parahippocampal gyrus, left medial frontal gyrus, and left inferior } \\
\text { frontal gyrus, and from the right amygdala to the left caudate, } \\
\text { right claustrum, and left inferior frontal gyrus increased. } \\
\text { In IGD adolescents, functional connectivity from the left amygdala } \\
\text { to the left frontal orbital gyrus, and from the right amygdala to the } \\
\text { right corpus callosum also increased. }\end{array}$ \\
\hline $\begin{array}{l}\text { Han et al, }{ }^{33} \\
2018\end{array}$ & $\begin{array}{l}\text { Resting-state functional } \\
\text { connectivity }\end{array}$ & $\begin{array}{l}30 \text { IGD } \\
30 \text { control participants }\end{array}$ & $\begin{array}{l}\text { IGD showed lower static functional connectivity between the right } \\
\text { DLPFC and the left rolandic operculum and higher static functional } \\
\text { connectivity between the right DLPFC and the left pars triangularis. } \\
\text { IGD had decreased dynamic functional connectivity between the } \\
\text { right DLPFC and the left insula, right putamen and left precentral } \\
\text { gyrus, and increased dynamic functional connectivity in the left } \\
\text { precuneus. } \\
\text { The dynamic functional connectivity between the right DLPFC and } \\
\text { the left insula was negatively correlated with the severity of IGD. }\end{array}$ \\
\hline $\begin{array}{l}\text { Wang et al, } \\
2019\end{array}$ & $\begin{array}{l}\text { Resting-state functional } \\
\text { connectivity and diffusion } \\
\text { tensor imaging-based } \\
\text { structural connectivity of } \\
\text { VTA/SN circuits }\end{array}$ & $\begin{array}{l}33 \text { male IGD } \\
28 \text { male control participants }\end{array}$ & $\begin{array}{l}\text { The nucleus accumbens and medial OFC showed lower resting- } \\
\text { state functional connectivity with VTA in IGD participants. } \\
\text { Resting-state functional connectivity strength of VTA-right nucleus } \\
\text { accumbens and VTA-left medial OFC correlated negatively with } \\
\text { internet addiction test score in IGD participants. } \\
\text { IGD participants showed lower structural connectivity in bilateral } \\
\text { VTA-nucleus accumbens tracts, but the connectivity did not } \\
\text { correlate with internet addiction test score. }\end{array}$ \\
\hline
\end{tabular}

Table II (continued). Studies of functional connectivity in fMRI. *Studies arranged chronologically by year. ACC, anterior cingulate cortex; DLPFC, dorsolateral prefrontal cortex; fMRI, functional magnetic resonance imaging; IGD, internet gaming disorder; OFC, orbitofrontal cortex; VMHC, voxel-mirrored homotopic connectivity; VTA/SN, ventral tegmental area/substantia nigra. Parts of Tables I and II reproduced with permission from ref 6: Weinstein A, Livny A, Weizman A. New developments in brain research of internet and gaming disorder. Neurosci Biobehav Rev. 2017;75:314-330. Copyright @ Elsevier 2017 


\section{Original article}

Neurobiological mechanisms underlying internet gaming disorder - Weinstein, Lejoyeux

\section{Studies of brain activation}

The aim of this section is to evaluate brain activation studies that measure and interpret the change between a baseline condition and a stimulation condition. Early studies (see review in ref 6) in IGD participants who were presented with gaming and neutral images during fMRI showed activation of brain regions associated with reward, response inhibition, and cognitive control, and the activation of these areas was associated with craving in response to the gaming images. Participants with IGD who played videogames for 6 weeks responded to videogame cues by showing increased reactivity in the OFC and ACC. Such cues activated regions associated with working memory, attention, and executive function in IGD. A positive relationship was noticed between the activation and cue-induced self-reported urges for gaming. Similar mechanisms of cue-induced reactivity of the frontal-limbic network were shown for gaming and smoking cues. Finally, exposure to figures from the World of Warcraft game activated the left caudate nucleus, parahippocampal gyrus, right hippocampus, right cuneus, right inferior parietal lobule, cerebellum, bilateral temporal cortex, and DLPFC, and activity in brain regions associated with motivation, emotion, and cognitive function was positively associated with craving. Recent studies have shown that watching video games activates brain regions associated with attention, executive function, and visuospatial orientation in individuals with IGD. ${ }^{40}$ They have also reported changes in attention to game images and in medial prefrontal cortex (MPFC) and ACC activation. ${ }^{40}$ Four functional connectivity networks related to the response to game cues showed altered engagement/disengagement in IGD. ${ }^{41}$ Finally, greater cue-induced activations within both the ventral and dorsal striatum were shown in IGD subjects. Activity within the left ventral striatum correlated negatively with cue-induced craving in IGD, and activations within the dorsal striatum had positive associations with duration of IGD play. These results suggest that a transition from ventral to dorsal striatal processing may occur in individuals with IGD. ${ }^{42}$

Players of massively multiplayer online role-play games (MMORPGs) have shown lower activity in areas associated with visuospatial attention and body self-awareness while reflecting on their own body image ${ }^{43}$ Furthermore, increased identification with one's avatar has been associ- ated with high left angular gyrus activation in pathological internet gamers. ${ }^{44}$ Evaluation of ideal self and actual self in young adults with IGD have been reported to be more negative than in healthy control participants, and fMRI-measured brain activity in the inferior parietal lobule found to be decreased, indicating dysfunctional emotional regulation. ${ }^{45}$ While thinking about their game characters, adolescents with IGD showed activation within MPFC and $\mathrm{ACC}$, indicating attachment to game figures that are equated with humans. ${ }^{46}$

Adolescents with IGD have also shown changes in emotional regulation, indicated by blunted neural responses within the striatum, insula, lateral prefrontal cortex, and $\mathrm{ACC}$ in response to negative affective cues and emotion regulation. ${ }^{47}$ Finally, impairment in executive function and related visual networks, as indicated by performance on the Stroop task in fMRI, has been reported. Adults with IGD showed impaired functional connectivity of the right executive control network, increased cognitive control processing, and diminished response inhibition. ${ }^{48}$

An early study (review in ref 6) by Dong et al, found that IGD subjects performing the Stroop task showed impaired response inhibition during exposure to gaming-cue distraction, revealed by higher activity in the posterior cingulate cortex and ACC. Participants with IGD showed stronger impulsivity and reduced activation of the supplementary motor areas while performing the Go/No-Go task. ${ }^{49}$ Adolescents with IGD showed activation in brain regions associated with attention and cognitive control during No-Go trials. ${ }^{50}$ During performance on the Go-Stop task, they showed reduced activation of the frontal-basal ganglia network and reduced inhibition of undesired movements, indicating that changes in the prefrontal cortex may be associated with impulsivity and impaired cognitive control. ${ }^{51}$ IGD participants processing social anxiety words showed decreased temporal gyrus activation. ${ }^{52}$

In summary, activation studies show evidence that individuals with IGD have impaired inhibition, a finding supported by meta-analysis. ${ }^{53}$ There is further evidence that videogame cues activate craving, as well as working memory, attention, and executive function. Some of these cognitive, sensory-motor, and emotional processes may not be associated with addiction per se but with changes to the brain as a result of prolonged exposure to screens. 


\section{Original article}

Neurobiological mechanisms underlying internet gaming disorder - Weinstein, Lejoyeux

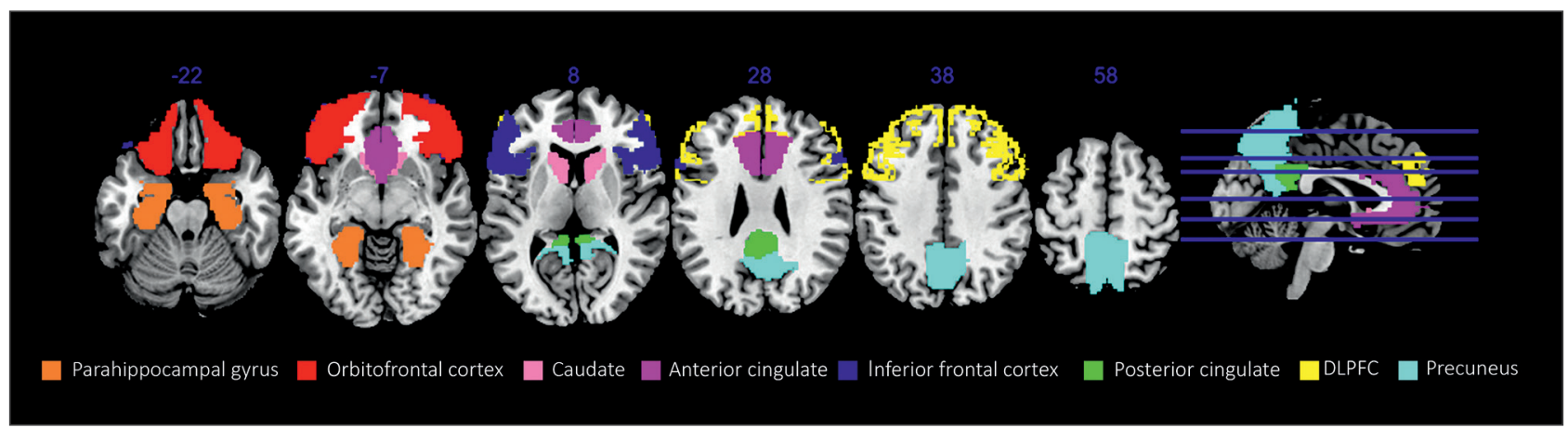

Figure 2. Regions that showed activation in response to internet and videogame cues in internet gaming disorder (IGD) participants in more than two studies. DLPFC, dorsolateral prefrontal cortex. Reproduced from ref 6: Weinstein A, Livny A, Weizman A. New developments in brain research of internet and gaming disorder. Neurosci Biobehav Rev. 2017;75:314-330. Copyright @ Elsevier 2017

Figure 2 shows brain regions activated in response to videogame cues in IGD players (reproduced with permission from Elsevier).

\section{Brain activation studies of reward and decision making}

The following section will describe studies of decision making and delay discounting in IGD. While performing a guessing task, IGD participants experienced monetary gain and loss. ${ }^{54}$ An early study by Dong et al (see review in ref 6) showed that with consecutive wins on a repeated-wins-and-losses task in fMRI, IGD participants had higher brain response in the ACC, insula, and inferior frontal cortex and lower brain response in the caudate and posterior cingulate cortex. After consecutive losses, they showed activation of the inferior frontal gyrus and deactivation of the posterior cingulate cortex. IGD participants preferred probable options to safe ones on a probability-discounting task, and they were faster than control subjects, indicating impulsive decision making. ${ }^{55}$ IGD participants also showed lower response in the inferior frontal gyrus and the precentral gyrus in response to options with varying probability. ${ }^{55}$ Compared with recreational internet game users, IGD participants preferred risky options to the fixed ones and spent less time in making risky decisions. ${ }^{56}$ This was indicated by stronger functional connectivity than seen in recreational internet game users in reward circuits and the executive control network and lower functional connectivity in the anterior salience network (ASN).
The behavioral performance and fMRI measures suggest that altered risk assessment might explain why individuals with IGD persist in playing online games in spite of detrimental consequences. IGD participants, while choosing probabilistic options, showed decreased activation in the inferior frontal gyrus and the precentral gyrus. They also preferred risk-disadvantageous choices and made quick, risky decisions without utilizing brain regions associated with impulse control. ${ }^{57}$ Similarly, decreased reward sensitivity and enhanced sensitivity to error monitoring regardless of satisfaction was indicated in adolescents who performed the probability-discounting task. ${ }^{58}$ There is also evidence that negative outcomes have influenced the covariance between the level of risk and the activation of brain regions associated with estimation of value, anticipation of reward, and learning, delineating the underlying neural mechanisms of risky decision making. ${ }^{59}$ IGD participants who performed on a delay-discounting task also showed stronger functional connectivity while selecting small and immediate gains. ${ }^{60}$ This is further evidence for augmented sensitivity to reward and decreased impulse control in IGD. ${ }^{60}$

IGD participants performing a decision-making task have shown lower changes in the DLPFC and inferior parietal lobule in response to risk exposure for potential losses and higher activity in response to reward in the OFC, ventromedial prefrontal cortex (vmPFC), and ventral striatum for potential gains during outcome processing. ${ }^{61}$ Participants with IGD and nicotine smokers who performed the delay-discounting task showed lower response accuracy in the DLPFC and vmPFC, and decoding accuracy in the 


\section{Original article}

Neurobiological mechanisms underlying internet gaming disorder - Weinstein, Lejoyeux

DLPFC was associated with impulsivity. ${ }^{62}$ To sum up, these studies suggest that IGD, similarly to other addictions, is associated with long-term changes in decision making and preference for immediate reward over long-term gains.

\section{Brain imaging studies on dopamine and serotonin}

Dopamine and serotonin (5-HT) have an important role in drug and alcohol dependence, in particular in reward and withdrawal mechanisms. This section will review brain imaging studies on dopamine and 5-HT in IGD. Early studies in IGD (review in ref 6) that included a small number of participants showed low levels of dopamine $\mathrm{D}_{2}$ receptor availability and dopamine transporter (DAT) availability in the striatum. A following study with a larger number of participants (12 with IGD and 14 control participants) measured dopamine $\mathrm{D}_{2}$ receptor and 5- $\mathrm{HT}_{2 \mathrm{~A}}$ receptor occupancy together with ${ }^{18} \mathrm{~F}$-fluorodeoxyglucose $\left({ }^{18} \mathrm{~F}-\mathrm{FDG}\right)$ to assess regional brain glucose metabolism via positron emission tomography. ${ }^{63}$ Results showed decreased glucose metabolism in the prefrontal, temporal, and limbic regions together with low dopamine $\mathrm{D}_{2}$ receptor availability in the striatum, which correlated with years of gaming. Reduced glucose metabolism in the OFC correlated with dopamine $\mathrm{D}_{2}$ receptor occupancy in the striatum. ${ }^{63}$ In summary, these results suggest that low levels of dopamine- $\mathrm{D}_{2}-$ and $5-\mathrm{HT}_{2 \mathrm{~A}}$-receptor occupancy together with dysregulation of the OFC could be an underlying mechanism of compulsive behavior and loss of control in IGD. ${ }^{63}$

\section{Discussion}

Similar to drug-abuse research, neuroimaging studies of reward have shown lower dopamine-transporter density and reduced occupancy of dopamine $\mathrm{D}_{2}$ receptors in the striatum, an area that mediates dopamine reward in IGD. This evidence is further supported by brain-activation studies showing that video game-playing stimuli activate the brain similarly to activation by drug cues. These studies show how cue exposure can affect the brain's reward, processing of sensory information, and self-reflection. There is also evidence for long-term changes as a result of play, indicated by an association between activity in the striatum and duration of IGD. Regular use of the internet for gaming was also associated with impulsivity and impaired cognitive control and impaired function of the prefrontal cortex in adults and adolescents. There is further evidence for lower connectivity in brain regions that are involved in cognitive control, executive function, and processing of motivation and reward that are also involved in substance-use disorders. This evidence provides strong support for the inclusion of IGD as a behavioral addiction alongside other behavioral addictions such as gambling disorder.

The brain changes that are associated with use of the Internet and videogames are not only associated with reward, but with a myriad of sensory, cognitive, and motor functions. Changes in the brain's resting state are associated with addiction, but also may result from enhanced sensory, cognitive, and motor effects on the brain. Similarly, structural changes in gray-matter volume and white-matter density are associated with addiction, but they are also associated with enhanced sensory, cognitive, and motor effects on the brain. Some of the changes in functional connectivity associated with motivation, craving, and reward are associated with addiction, whereas others may result from changes in executive function and sensory-motor processing that are not related to addiction per se. Activation studies demonstrate changes in body image, adoption of a virtual self, and experience of emotional changes that are unique to multiplayer gaming. Playing computer games online activates many brain areas responsible for cognitive, motor, and sensory function that are not directly involved in addiction, indicating the pervasive effects of screen use on the brain.

Studies of comorbidity of IGD with attention deficit-hyperactivity disorder (ADHD) and depression have provided new insights into the brain mechanisms that underlie these disorders. Executive control mechanisms in ADHD may increase susceptibility to develop IGD. ${ }^{64}$ Adolescents with ADHD may play cyber games to increase their capacity to focus their attention. ${ }^{65}$ IGD participants with ADHD had larger gray-matter volume in the right precuneus and smaller gray-matter volume in the right inferior frontal gyrus than IGD participants without ADHD and control participants. ${ }^{66}$ Patients with ADHD and IGD who were treated with cognitive behavioral therapy and medication showed improved functional connectivity between the cortex and subcortex in all ADHD and IGD patients, with good prognoses after 1-year treatment. ${ }^{67}$ IGD patients with a major depressive episode had an impaired ability to inhibit activity in the hippocampus while performing the Wisconsin Card-Sorting Test. ${ }^{68}$ Furthermore, they showed diminished functional connectivity with 


\section{Original article}

Neurobiological mechanisms underlying internet gaming disorder - Weinstein, Lejoyeux

the prefrontal cortex. ${ }^{69}$ Treatment of IGD was associated with decreased connectivity between the amygdala and the middle frontal and precentral gyrus. Impaired functional connectivity between executive control and emotional mechanisms, a characteristic of depression, can be ameliorated in IGD. ${ }^{70}$ IGD participants also showed greater functional connectivity of brain areas involved in executive control that are associated with comorbid ADHD and depressive disorder. ${ }^{71}$

\section{Conclusions}

Studies thus far have shown reward deficiency, reduced impulse control mechanisms, impaired decision making, and impulsivity in IGD. Studies on comorbidity of IGD and ADHD indicate that executive control networks in ADHD may increase the susceptibility to develop IGD. Similarly to depression, IGD can be ameliorated by treating dysfunctional connectivity between emotion and executive control mechanisms. Finally, the neurobiological mechanisms of IGD and excessive use of digital media require further examination, in particular in young children and adolescents since it expands to domains such as media, social communication, and multitasking, with deleterious effects on reading and executive function.

Acknowledgments/Disclosures: All individuals included as authors of the paper have contributed substantially to the scientific process leading up to the writing of the paper. The authors have no interests or activities that might be seen as influencing the research (eg, financial interests in a test or procedure, funding by pharmaceutical companies for research).

\section{References}

1. Hutton JS, Dudley J, Horowitz-Kraus T, et al. Associations between screen-based media use and brain white matter integrity in preschool-aged children. JAMA Pediatr. 2020;174(1):e193869.

2. Paulus MP, Squeglia LM, Bagot K, et al. Screen media activity and brain structure in youth: evidence for diverse structural correlation networks from the ABCD study. Neuroimage. 2019;185:140-153.

3. Ophir E, Nass C, Wagner AD. Cognitive control in media multitaskers. Proc Natl Acad Sci U S A. 2009; 106(37):15583-15587.

4. Uncapher MR, Wagner AD. Media multitasking, mind, and brain. Proc Natl Acad Sci U S A. 2018; 115(40):9889-9896.

5. Yao YW, Liu L, Ma SS. Functional and structural neural alterations in Internet gaming disorder: a systematic review and meta-analysis. Neurosci Biobehav Rev. 2017:83:313-324. doi:10.1016/j.neubiorev. 2017.10.029.

6. Weinstein A, Livny A, Weizman A. New developments in brain research of internet and gaming disorder. Neurosci Biobehav Rev. 2017;75:314-330. doi:10.1016/j.neubiorev.2017.01.040.

7. Weinstein A. An update overview on brain imaging studies of Internet Gaming Disorder. Front Psychiatry. 2017;8:185. doi:10.3389/fpsyt.2017.00185.

8. Kuss DJ, Pontes HM, Griffiths MD. Neurobiological correlates in internet gaming disorder: a systematic literature review. Front Psychiatry. 2018;9:166. doi:10.3389/fpsyt.2018.00166. eCollection 2018.

9. Kim H, Kim YK, Gwak AR, et al. Resting-state regional homogeneity as a biological marker for patients with Internet gaming disorder: a comparison with patients with alcohol use disorder and healthy controls. Prog Neuropsychopharmacol Biol
Psychiatry. 2015;60;104-111. doi:10.1016/j.pnpbp. 2015.02.004.

10. Sun Y, Wang Y, Han X, et al. Sex differences in resting-state cerebral activity alterations in internet gaming disorder. Brain Imaging Behav. 2019;13(5):1406-1417. doi:10.1007/s11682-0189955-4.

11. Sun Y, Sun J, Zhou Y, et al. Assessment of in vivo microstructure alterations in gray matter using DKI in Internet gaming addiction. Behav Brain Funct. 2014; $10: 37$

12. Wang $\mathrm{H}$, Jin $\mathrm{C}$, Yuan $\mathrm{K}$, et al. The alteration of gray matter volume and cognitive control in adolescents with Internet gaming disorder. Front Behav Neurosci. 2015;9:64.

13. Lin X, Dong G, Wang Q, et al. Abnormal gray matter and white matter volume in Internet gaming addicts. Addict Behav. 2015;40:137-143.

14. Takeuchi H, Taki Y, Hashizume H, et al. Impact of videogame play on the brain's microstructural properties: cross-sectional and longitudinal analyses. Mol Psychiatry. 2016;21(12):1781-1789. doi:10.1038/ mp.2015.193.

15. Yuan K, Qin W, Yu D, et al. Core brain networks interactions and cognitive control in Internet gaming disorder individuals in late adolescence/early adulthood. Brain Struct Funct. 2016;221(3):1427-1442. 16. Zhai J, Luo L, Qiu L, et al. The topological organization of white matter network in internet gaming disorder individuals. Brain Imaging Behav. 2017; 11(6):1769-1778, doi:10.1007/s11682-016-9652-0.

17. Jeong BS, Han DH, Kim SM, et al. White matter connectivity and Internet gaming disorder. Addict Biol. 2016;21(3):732-742. doi:10.1111/adb.12246.

18. Seok JW, Sohn JH. Altered gray matter volume and resting-state connectivity in individuals with internet gaming disorder: a voxel-based morphometry and resting-state functional magnetic resonance imaging study. Front Psychiatry. 2018;9:77. doi:10.3389/ fpsyt.2018.00077.

19. Pan N, Yang Y, Du X, et al. Brain structures associated with internet addiction tendency in adolescent online game players. Front Psychiatry. 2018;9:67. doi:10.3389/fpsyt.2018.00067.

20. Lee D, Park J, Namkoong K, Kim IY, Jung YC. Gray matter differences in the anterior cingulate and orbitofrontal cortex of young adults with Internet gaming disorder: surface-based morphometry. J Behav Addict. 2018;7(1):21-30. doi:10.1556/ 2006.7.2018.20

21. Dong G, Wu L, Wang Z, Wang Y, Du X, Potenza MN. Diffusion-weighted MRI measures suggest increased white-matter integrity in Internet gaming disorder: evidence from the comparison with recreational Internet game users. Addict Behav. 2018:81:32-38. doi:10.1016/j.addbeh.2018.01.030. 22. Wang Z, Wu L, Yuan K, et al. Cortical thickness and volume abnormalities in Internet gaming disorder: evidence from comparison of recreational Internet game users. Eur J Neurosci. 2018 Jun 8. Epub ahead of print. doi:10.1111/ejn.13987.

23. Wang S, Liu J, Tian L. Increased insular cortical thickness associated with symptom severity in male youths with internet gaming disorder: a surfacebased morphometric study. Front Psychiatry. 2018; 9:99. doi:10.3389/fpsyt.2018.00099. eCollection 2018.

24. Kuhn S, Romanowski A, Schilling C, et al. The neural basis of video gaming. Transl Psychiatry. 2011; e53.

25. Wang L, Wu L, Lin X, et al. Altered brain functional networks in people with Internet gaming dis- 


\section{Original article}

Neurobiological mechanisms underlying internet gaming disorder - Weinstein, Lejoyeux

order: evidence from resting-state fMRI. Psychiatry Res Neuroimaging. 2016;254:156-163. doi:10.1016/j. pscychresns.2016.07.

26. Dong G, Lin X, Potenza MN. Decreased functional connectivity in an executive control network is related to impaired executive function in Internet gaming disorder. Prog Neuropsychopharmacol Biol Psychiatr. 2015;3(57):76-85.

27. Wee CY, Zhao Z, Yap PT, et al. Disrupted brain functional network in Internet addiction disorder: a resting-state functional magnetic resonance imaging study. PLoS One. 2014;9(9):e107306.

28. Yuan $\mathrm{K}, \mathrm{Yu} \mathrm{D}, \mathrm{Cai} \mathrm{C}$, et al. Frontostriatal circuits, resting state functional connectivity and cognitive control in internet gaming disorder. Addict Biol. 2017;22(3):813-822. doi:10.1111/adb.12348.

29. Jin $C$, Zhang T, Cai $C$, et al. Abnormal prefrontal cortex resting state functional connectivity and severity of internet gaming disorder. Brain Imaging Behav 2016;10(3):719-729. doi:10.1007/s11682-015-9439-8. 30. Zhang JT, Yao YW, Li CS, et al. Altered resting-state functional connectivity of the insula in young adults with Internet gaming disorder. Addict Biol. 2016;21(3):743-751. doi:10.1111/adb.12247.

31. Wang R, Li M, Zhao M, et al. Internet gaming disorder: deficits in functional and structural connectivity in the ventral tegmental area-accumbens pathway. Brain Imaging Behav. 2019;13(4):1172-1181. doi:10.1007/s11682-018-9929-6.

32. Kang KD, Jung TW, Park IH, Han DH. Effects of equine-assisted activities and therapies on the affective network of adolescents with internet gaming disorder. J Altern Complement Med. 2018;24(8): 841-849. doi:10.1089/acm.2017.0416.

33. Han X, Wu X, Wang Y, et al. Alterations of resting-state static and dynamic functional connectivity of the dorsolateral prefrontal cortex in subjects with internet gaming disorder. Front Hum Neurosci. 2018;12:41. doi:10.3389/fnhum.2018.00041.

34. Du X, Yang Y, Gao P, et al. Compensatory increase of functional connectivity density in adolescents with internet gaming disorder. Brain Imaging Behav. 2017;11(6):1901-1909. doi:10.1007/s11682016-9655-X.

35. Ko CH, Hsieh TJ, Wang PW, et al. Altered gray matter density and disrupted functional connectivity of the amygdala in adults with Internet gaming disorder. Prog Neuropsychopharmacol Biol Psychiatry. 2015:57:185-192.

36. Park CH, Chun JW, Cho H, Jung YC, Choi J, Kim DJ. Is the Internet gaming-addicted brain close to be in a pathological state? Addict Biol. 2017;22(1): 196-205. doi:10.1111/adb.12282.

37. Chen X, Wang Y, Zhou Y, et al. Different resting-state functional connectivity alterations in smokers and nonsmokers with Internet gaming addiction. Biomed Res Int. 2014;2014:825787.

38. Hong SB, Harrison BJ, Dandash O, et al. A selective involvement of putamen functional connectivity in youth with internet gaming disorder. Brain Res. 2015;1602:85-95.

39. Wang Y, Yin Y, Sun YW, et al. Decreased pre- frontal lobe interhemispheric functional connectivity in adolescents with internet gaming disorder: a primary study using resting-state FMRI. PLoS One. 2015;10(3): 0118733

40. Cai C, Yuan K, Yin J, et al. Striatum morphometry is associated with cognitive control deficits and symptom severity in Internet gaming disorder. Brain Imaging Behav. 2016;10(1):12-20. doi:10.1007/ s11682-015-9358-8.

41. Liu J, Li W, Zhou S, et al. Functional characteristics of the brain in college students with Internet gaming disorder. Brain Imaging Behav. 2016;10(1):60-7. doi:10.1007/s11682-015-9364-x

42. Ma SS, Worhunsky PD, Xu JS, et al. Alterations in functional networks during cue-reactivity in Internet gaming disorder. J Behav Addict. 2019;8(2): 277-287. doi:10.1556/2006.8.2019.25.

43. Liu L, Yip SW, Zhang JT, et al. Activation of the ventral and dorsal striatum during cue reactivity in Internet gaming disorder. Addict Biol. 2017;22(3): 791-801. doi:10.1111/adb.12338

44. Leménager T, Dieter J, Hill H. Neurobiological correlates of physical self-concept and selfidentification with avatars in addicted players of Massively Multiplayer Online Role-Playing Games (MMORPGs). Addict Behav. 2014;39(12): 1789-1797.

45. Leménager T, Dieter J, Hill H, et al. Exploring the neural basis of avatar identification in pathological Internet gamers and of self-reflection in pathological social network use. J Behav Addict. 2016;5(3): 485-99. doi:10.1556/2006.5.2016.048.

46. Kim MK, Jung YH, Kyeong S, Shin YB, Kim E, Kim JJ. Neural correlates of distorted self-concept in individuals with internet gaming disorder: a functional MRI study. Front Psychiatry. 2018;9: 330. doi:10.3389/fpsyt.2018.00330.

47. Choi EJ, Taylor MJ, Hong SB. Gaming-addicted teens identify more with their cyber-self than their own self: neural evidence. Psychiatry Res Neuroimaging. 2018;279:51-59. doi:10.1016/j.pscychresns.2018.05.012.

48. Yip SW, Gross JJ, Chawla M. Is neural processing of negative stimuli altered in addiction independent of drug effects? Findings from drug-naïve youth with internet gaming disorder. Neuropsychopharmacol. 2018;43(6):1364-1372. doi:10.1038/ npp.2017.28.

49. Wang L, Zhang Y, Lin X, Zhou H, Du X, Dong G. Group independent component analysis reveals alternation of right executive control network in Internet gaming disorder. CNS Spectr. 2018;23(5):300-310. doi:10.1017/S1092852917000360.

50. Chen CY, Huang MF, Yen JY, et al. Brain correlates of response inhibition in Internet gaming disorder. Psychiatry Clin Neurosci. 2015;69(4): 201-209.

51. Ding WN, Sun JH, Sun YW, et al. Trait impulsivity and impaired prefrontal impulse inhibition function in adolescents with internet gaming addiction revealed by a Go/No-Go fMRI study. Behav Brain Funct. 2014;10:20.
52. Li B, Friston KJ, Liu J, et al. Impaired frontal-basal ganglia connectivity in adolescents with internet addiction. Sci Rep. 2014;4:5027.

53. Dieter J, Hoffmann S, Mier D, et al. The role of emotional inhibitory control in specific internet addiction - an fMRI study. Behav Brain Res. 2017;324: 1-14. doi:10.1016/j.bbr.2017.01.046.

54. Argyriou E, Davison CB, Lee TTC. Response inhibition and internet gaming disorder: a meta-analysis. Addict Behav. 2017;71:54-60. doi:10.1016/j. addbeh.2017.02.026.

55. Dong G, Huang J, Du X. Enhanced reward sensitivity and decreased loss sensitivity in Internet addicts an fMRI study during a guessing task. J Psychiatr Res. 2011;45(11):1525-1529.

56. Lin X, Zhou H, Dong G, Du X. Impaired risk evaluation in people with Internet gaming disorder: fMRI evidence from a probability discounting task. Prog Neuropsychopharmacol Biol Psychiatr. 2015;56:142-148

57. Wang Z, Liu X, Hu Y, Zheng H, Du X, Dong G. Altered brain functional networks in Internet gaming disorder: independent component and graph theoretical analysis under a probability discounting task. CNS Spectr. 2019;24(5):544-556.

58. Dong G, Potenza MN. Risk-taking and risky decision-making in Internet gaming disorder: Implications regarding online gaming in the setting of negative consequences. J Psychiatr Res. 2016;73:1-8. doi:10.1016/j.jpsychires.2015.11.011.

59. Kim JE, Son JW, Choi WH, et al. Neural responses to various rewards and feedback in the brains of adolescent Internet addicts detected by functional magnetic resonance imaging. Psychiatr Clin Neurosci. 2014;68(6):463-470. doi:10.1111/ pcn.12154.

60. Qi X, Yang Y, Dai S, et al. Effects of outcome on the covariance between risk level and brain activity in adolescents with internet gaming disorder. Neuroimage Clin. 2016;12:845-851. eCollection 2016

61. Wang Y, Wu L, Zhou H, et al. Impaired executive control and reward circuit in Internet gaming addicts under a delay discounting task: independent component analysis. Eur Arch Psychiatry Clin Neurosci. 2017;267(3):245-255. doi:10.1007/s00406-016$0721-6$.

62. Liu L, Xue G, Potenza MN, et al. Dissociable neural processes during risky decision-making in individuals with Internet-gaming disorder. Neuroimage Clin. 2017;14:741-749. doi:10.1016/j.nicl.2017. 03.010.

63. Zha R, Bu J, Wei Z, et al. Transforming brain signals related to value evaluation and self-control into behavioral choices. Hum Brain Mapp. 2019;40(4):1049-1061. doi:10.1002/hbm.24379. 64. Tian M, Chen Q, Zhang Y, et al. PET imaging reveals brain functional changes in internet gaming disorder. Eur J Nucl Med Mol Imaging. 2014;41(7):1388-1397.

65. Park JH, Hong JS, Han DH, et al. Comparison of QEEG findings between adolescents with atten- 


\section{Original article}

Neurobiological mechanisms underlying internet gaming disorder - Weinstein, Lejoyeux

tion deficit hyperactivity disorder (ADHD) without comorbidity and ADHD comorbid with Internet gaming disorder. J Korean Med Sci. 2017;32(3):514-521. doi:10.3346/jkms.2017.32.3.514.

66. Lee D, Namkoong K, Lee J, Jung YC. Preliminary evidence of altered gray matter volume in subjects with internet gaming disorder: associations with history of childhood attention-deficit/ hyperactivity disorder symptoms. Brain Imaging Behav. 2019;13(3):660-668. doi:10.1007/s11682018-9872-6.

67. Han DH, Bae S, Hong J, et al. Resting-state
fMRI study of ADHD and internet gaming disorder. J Atten Disord. 2019 Oct 23. Epub ahead of print. doi:10.1177/1087054719883022.

68. Han DH, Kim SM, Bae S, Renshaw PF, Anderson JS. A failure of suppression within the default mode network in depressed adolescents with compulsive Internet game play. J Affect Disord. 2016;194:57-64. doi:10.1016/j.jad.2016.01.013.

69. Lee D, Lee J, Namkoong K, Jung YC. Subregions of the anterior cingulate cortex form distinct functional connectivity patterns in young males with internet gaming disorder with comorbid depres- sion. Front Psychiatry. 2018;9:380. doi:10.3389/ fpsyt.2018.00380.

70. Liu L, Yao YW, Li CR, et al. The comorbidity between internet gaming disorder and depression: interrelationship and neural mechanisms. Front Psychiatry. 2018;9:154. doi:10.3389/fpsyt.2018. 00154.

71. Han DH, Kim SM, Bae S, Renshaw PF, Anderson JS. Brain connectivity and psychiatric comorbidity in adolescents with Internet gaming disorder. Addict Biol. 2017;22(3):802-812. doi:10.1111/ adb.12347. 